\title{
Imparting Indigenous Knowledge through Traditional Forms of Entertainment: The Role of Ewe Play Games
}

\author{
Martin Q. Amlor, ${ }^{1, *}$ \\ ${ }^{1}$ Centre for African and International Studies, University of Cape Coast, Cape Coast, Ghana \\ *Correspondence: Centre for African and International Studies, University of Cape Coast, Cape Coast, Ghana. Tel: \\ 233-244-818-485. E-mail: fmqamlor@yahoo.com
}

Received: May 31, 2016

doi:10.5430/wjss.v3n2p63

\author{
Accepted: July 10, 2016 \\ Online Published: July 20, 2016 \\ URL: http://dx.doi.org/10.5430/wjss.v3n2p63
}

\begin{abstract}
Indigenous knowledge, perceived as cultural norms and values that collectively inform, educate and give identity to people in a society, still remains an African cultural legacy. Unfortunately, Western culture in contemporary Ghana, is speedily competing with, and almost stunting the growth and survival of African indigenous knowledge systems. This unpleasant situation has led to a re-awakening among the Ewe ethnic society to go back to her roots to revive indigenous entertainment forms like play games to promote the teaching, learning and preservation of indigenous education. The major concern of this paper is to identify some popular Ewe play and singing games and describe how activities in them in terms of their forms, participants, equipment, rules/codes of play, socio-cultural settings within which they are performed help to educate, nurture, shape and equip the youth or children to take up future adult roles in the society.
\end{abstract}

Keywords: indigenous knowledge, entertainment, play and singing games, society

\section{Introduction}

The connection between play and culture has an illustrious past (Holmes, 2011). The classic play theorist, Huizinga (1950) articulates the position of play as a cultural phenomenon that both humans and animals share. Garvey (1990) corroborates Huizinga's position and opines: "play is not just a past time activity, but a useful cultural tool that satisfies certain needs and purposes of adults, adolescents, children and cognitively, advanced non-human species such as primates. In the absence of written records in the past, Kenyatta (2004) and Ndee (2010), state that the cultural traditions of Africans were transmitted from one generation to the other through the use of memory, verbal communication and specific activities. There were, therefore, a number of cultural elements that facilitated cognitive development to enhance recall and communication of facts. Some of these cultural elements included games, stories, songs and dances (Wanderi, 2001 and 2011, Kenyatta, 2004). These cultural elements are considered crucial as they teach, bear meaning and understanding within African cultural context and project the identity of the people.

Among the Ewes of Ghana, the youth or children's indigenous forms of entertainment which among others include play and singing games, go a long way to teach and give them in-depth understanding and, as well, measure their creative aesthetic values of their folklore which have in-built specifications and mechanisms that render it culture-specific. According to Cheska (1987), "in making reference to socio-cultural games, the use of songs and dance together with other related art forms like ornamentation, drama and literature are elements that enforce the beliefs and satisfy the needs of the society in which the performers are located". Similarly, these forms of entertainment among the young ones in Eweland, are perceived as miniature windows through which values, behaviour and societal ethics of the people are observed. Stressing further why societies in contemporary Africa still engage in indigenous forms of entertainment, Nyato and Mpara (2008) cite the case of children's play and singing games of the Shona of Zimbabwe:

Knowledge expressed in play and singing games are accessed through children's play activities which provide social context for the accumulation of cherished socio-cultural virtues and values which comprise good behaviour, discipline, hard work and competitive spirit, encountering and handling issues of success 
and failure as well as assuming leadership roles. On the whole, these games reflect the indigenous education embedded in the society of the people.

\section{Methodology}

The author undertook an ethnographic study by employing three main approaches to gathering data: conducting personal interviews with both the elderly and the youth whose ages fall within the age brackets of 40-70 and 14-39 years respectively, engaging in focus group discussions with few selected elders who have in-depth knowledge of the indigenous play and singing games which were the focus of the research in the study area. This research tool was quite critical, since interviewing, as put by Fontana and Frey (1994), is a potent means of understanding fellow human beings. The adoption of the participant observation research approach; where observation as explained by Creswell (2005) aims at gathering first-hand information by perceiving people and their intra-actions at the research site as well as socializing and participating in their work activities, enabled the author to arrive at a definite and reliable conclusion drawn to represent a fair assessment of the topic and its main objective. In addition, other secondary sources of data were used to support the result of the research.

\section{What are Traditional Play Games?}

These are structured forms of recreational physical activities which according to Mwenda (2011), "are guided by formal or informal rules, by which participants must abide. They can, therefore, be categorised as competitive or non-competitive activities which a participant may engage in for a number of reasons such as prestige, recognition, status or a combination of these. Play games are not only sources of leisure but also avenues for acquiring indigenous knowledge that forms part of the culture of a people". Sutton-Smith et al (1995) define a play-game as "a competitive activity in which participants contend with each other according to a set of rules. As structured forms of activity performed for enjoyment, play games serve as educational tools".

The Merriam-Webster Dictionary (2016) explains play games as activities that children or the youth undertake and most often, accompany these actions with singing of narrative songs. It can, therefore, be realised in African societies that both play and singing games are worth more than just passing time with. Folklorists, ethnologists and psychologists do not only see these activities as important part of childhood culture but also as activities that are important cultural tools of socialisation and a repository of native education that enhances cultural construction and perpetuation of societal values which shape the total being of the young as they grow into maturity.

Frimpong-Nnuroh (2010) emphasises the above point that "games as forms of entertainment constitute part of indigenous knowledge that are directed at satisfying specific needs of traditional societies through agents of socialisation such as learning from the elders, and peers especially when they take part in communal activities such as listening to folktales and participating in music and dance activities on moonlit nights. All these activities are ways of imparting native education to children in order to shape and mould their formative stages of life".

\subsection{Structure of Ewe Play-Games}

Play games in Eweland have been structured and targeted towards providing amusement and other socio-cultural values to both the young and old. The socio-cultural settings within which the games are performed include those outlined below:

Each gender or people of different age categories perform different types of games. There are games that are exclusively performed by children or the youth who are entirely males or females or both. Like in other socities, plays are commonly associated with childhood activities in Eweland because during their formative stages, children's knowledge of self, gaining and understanding of verbal and non-verbal discourse that are linked to the physical and social worlds expand extensively. Games that are restricted to males are deemed as energetic and laden with physical strength. The games are most often performed in the dry season when there is less work on the farms and thus, providing the young ones the opportunity to play under moonlit nights. Munyao (2010) similarly states that African indigenous game performances are often held during the dry season as compared to lesser participation during the rainy season.

The evenings are seen as most suitable for performing the games because by that time, households finish their domestic activities and their evening meals. This invariably means that the participants, who gather for the games from different homes, would all be available. However, there is the possibility for a parent to prevent his/her child from participating in a game on the simple basis of not finishing the work assigned him/her at home. The aim of 
joining fellow colleagues to play and have fun peps one up to hurry up with the household chores and thus, motivates the participants to complete household duties in good time. Although the evening offers a socially convenient time for most Ewe play games to take place, there are some of them which the society frowns upon at that period because of the lot of cacophony they generate. An interesting phenomenon which often forms part of the structure of play games is music that is incorporated into them. Singing, hand clapping and dancing in most cases charge the atmosphere and boost performance zeal in individual participants. The pedagogical values gained by the participants, are intrinsically woven into the structure of the games.

The structure of the games also consists of rules which govern their successful organization and performances. The rules which often, are known by the participants regulate their attitude, commitment, discipline and respect and tolerance for fellow participants during the play sessions. In most cases, to eliminate doubt and possible misunderstandings which centre on what a participant may deem as a breach of the rule or otherwise, requires that the rules are outlined before the commencement of every game. The rules, therefore, generate in the participants, strong inner feelings, spirit of gregariousness, self-discipline and impetus which propel them to undertake physical and mental exercises by the use of their bodies which develop and improve their health status.

\subsection{Origin of the names Ewe Play-Games}

The names of some Ewe play games, according to oral tradition, originated from the nature of activity involved in the games, from the song texts used in the games and from catchy phrases that are shouted out during the games. Other signals employed in the games are derived from onomatopoeiac words or phrases which children decode and assign meanings to. Examples include tototo (ready?), yayaya (yes), kooko (finished?) and akaee (I/We have won).

The paper now examines six popular Ewe play games; Ka asi atiasimake (Touch the untouchable tree), Amesi wodzi Dzo qa (Whoever is born on Monday), Đevi-metsitsiwo (Children as adults), Gbstokrolo (Puberty initiates' singing game), Sibesibe (Run and hide) and Dae de megbe (Deposit it from behind), and describe how activities in them in terms of their forms, participants, equipment, rules/codes of play, socio-cultural settings within which they are performed and their functions in the socio-cultural lives of both the participants and the society.

\subsection{Ka asi ati asimake}

A play-game that is well patronised on moonlit nights by young boys and girls who have attained the age of six years and above, is Ka asi ati asimake. This game which has a membership of eight to fifteen participants requires individual tact, agility, thoughtfulness, good sense of judgment and swift footedness as skills that propel a participant to emerge a winner.

Before the game begins, a tree is located on the play ground and named as the 'untouchable tree'. One participant voluntarily offers him/herself as the AtimudzJla (a guard), and stands near the tree to prevent his/her colleagues from touching it when the game begins. The music and text of the song below is sung in a call and response form between the guard who acts as the lead singer and the rest of the Et Jwo (group members). Each line of the song text sung by the Atiyudzsla, is immediately followed by a succeeding line which is sung by the rest of the group members as a response to the lead singer's call. Getting to the end, the guard sings tototo, as a signal call to 'get ready', and the rest of the group members respond to it by singing ya-ya, meaning yes, yes to begin the game.

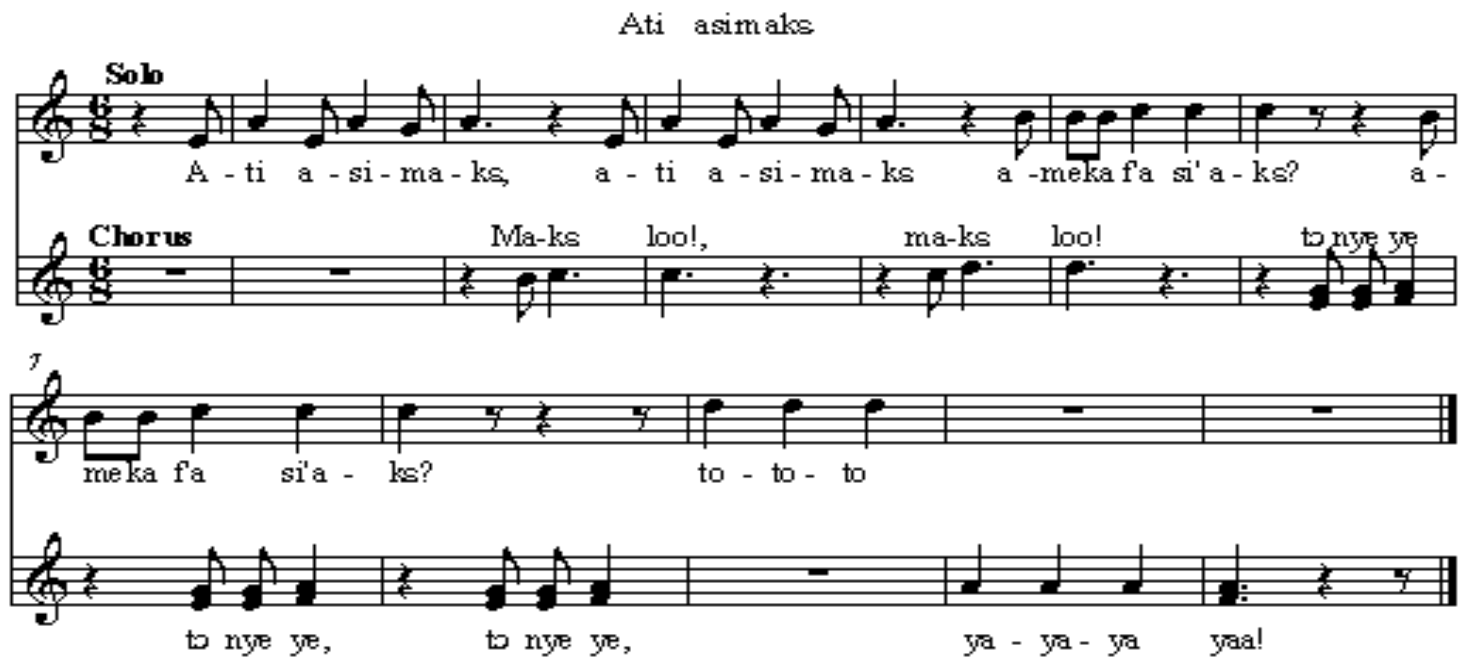


Example 1: A song that is sung to mark the commencement of the game; ati asimake.

\begin{tabular}{|c|c|c|}
\hline Atimudzsla: & //:Ati asimake & Guard: //:The untouchable tree \\
\hline EtJwo: & Ma-ke loo!:// & Group members: The untouchable!:// \\
\hline Atimudzsla: & Meka f'a sie ake? & Guard: Whose hand can touch the untouchable tree? \\
\hline EtJwo: & Tonye ye & Group members: It's mine \\
\hline Atiyudzsla & To-to-to & Guard: To-to-to (onomatopoeia) \\
\hline EtJwo: & Ya-ya-ya! & Group members: Yes-yes-yes! \\
\hline
\end{tabular}

While the guard keeps watch by standing closely to the tree, his colleagues, on the other hand, make frantic efforts by adopting tactical and swift body movements to cautiously and quietly tip-toe or run very fast to touch the tree from the blind side of the guard.

\subsubsection{Rules Governing the Game}

A member, who is caught by the guard in an attempt to touch the tree, is immediately eliminated from further participating in the game. A participant also faces dismissal from the game if it is detected that he/she lends $\mathrm{him} / \mathrm{h}$ erself easily to be caught by the guard in course of the game. Furthermore, no guard has the authority to beat or maltreat a participant during the discharge of his/her duties. A guard who contravenes the rules faces instant exit from the game. On the other hand, a guard who the group sees as inactive in the discharge of his/her duties, is immediately relieved of the post. The game continues until the participants become tired and retire. Participants who succeed in touching the untouchable tree without being caught, are declared the smartest and winners of the game.

\subsubsection{Cultural Relevance of Ka asi ati asimake}

Since the game involves movements such as running, squatting and jumping, these vigorous physical exercises according to Wanderi (2011) enhance cardiovascular and musculosketal strength which in the past, were vital requirements for local warriors. The Ewes, also believe that the survival of their communities is highly dependent on the empowerment of individual citizens in terms of general physical fitness. Besides its entertaining nature, the game instills truth, discipline, commitment and respect for colleagues. Since the rules governing the game are never bent in favour of those who flout them, participants who insult, quarrel or inflict physical pain on fellow colleagues, or touch the tree before the signal is given, are charged with insincerity and indiscipline and are instantly expelled from further partaking in the game. The rules of the above game, therefore, help children to grow up with sterling societal values or attitudes that nurture and shape them not only as acceptable citizens of the society, but also as responsible future leaders who can take charge of the administration of the Ewe society anchored on truth, self-discipline, commitment, respect, peer tolerance and unity of purpose as one people.

\subsection{Amesi wodzi Dzoda}

This is an indigenous singing game that entertains and, teaches children in the age bracket of four to six or seven years, the concept of name and identity through music and dance. In other words, the game offers an easy and quick means of learning and acquiring indigenous education about correct pronunciation of local Ewe names of the days as well as the birthday names associated with each day of the week. The game commences when the participants, both boys and girls, position themselves in a circle in an open place in the community. One person, who is chosen as the leader/cantor, stands in the middle of the circle, and tunes up the opening session (the first line) of the song before the rest of the participants join in to sing the remaining portion of the song to the end in a call and response form. While the first line of the song text is repeated, all the participants, (both male and female) born on Monday, move briskly and enter the circle, and amidst singing, they hold and wriggle their hips. Upon reaching the last line of the song (akpJ dzidzJ hee!), they jump high, clap their hands and move back to their former positions in the circle to make way for other colleagues born on other days of the week, to take their turn. 
Amesi wodri Droda
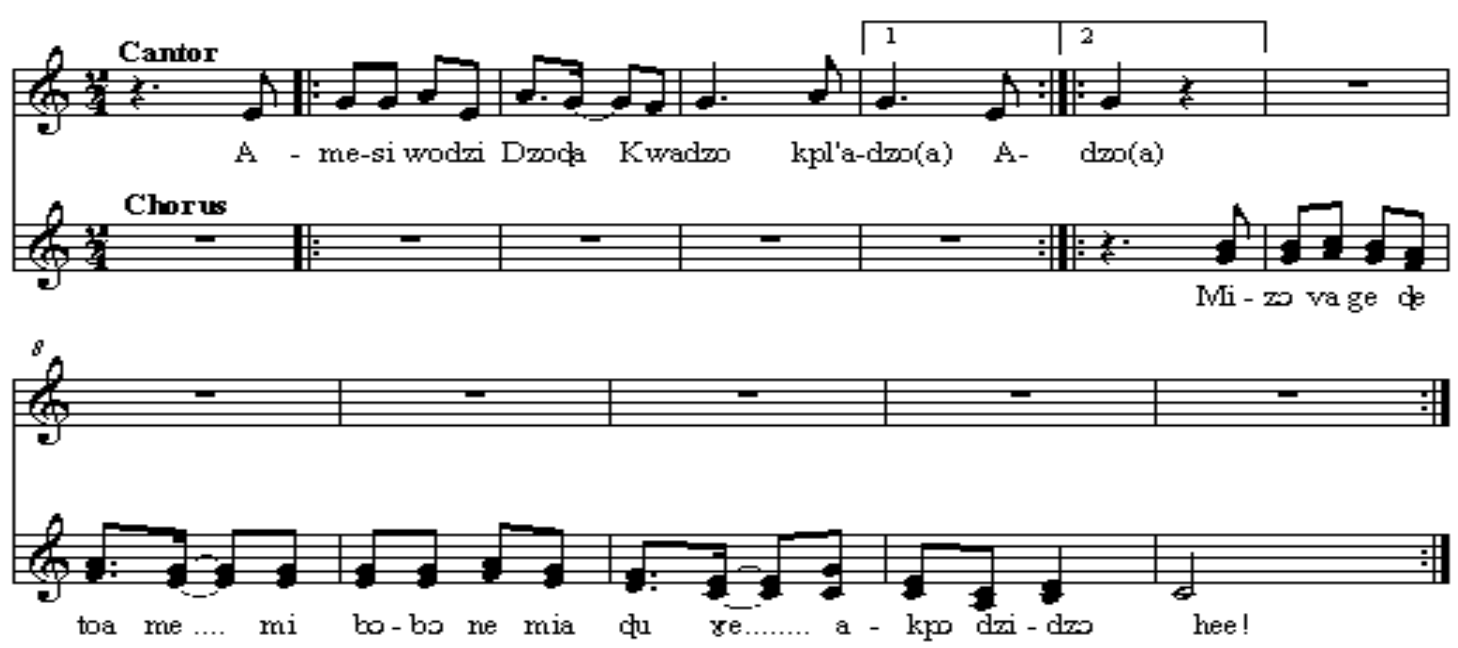

Example 2: A song depicting local Ewe birthday names and names of the days of the week.

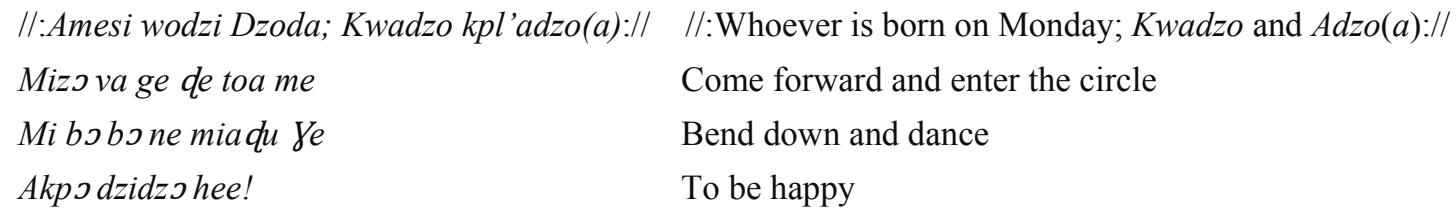

\subsubsection{The Rule of the Game}

The rule of the game forbids members who have already had their chance from joining fresh participants to perform in the circle. The game finally ends after all the participants have had their turn to accompany their birthday names with music and dance in the circle.

\subsubsection{The Socio-Cultural Role}

The ultimate benefit acquired from the above game is the immense education it provides the younger ones to know and pronounce correctly, the local names of the week and also memorise easily, the local male and female birthday names associated with each day of the week. For the above reason, younger participants have the opportunity to listen to their elder brothers and sisters, by imitating their language speech patterns as well as their musical behaviour in order to speak eloquently, words or phrases in which the music is couched. Musical behaviour and other forms of social behaviour acquired from infancy is considered as a vital asset that acculturates and mould children to be future custodians of their indigenous education including their music and dance types. Furthermore, acquisition of indigenous education is also seen in the musical behaviour of Ewe children in other forms of games. For example, children perform games under the guise of being adults. A typical example of a role play-game in which children pretend to be adult men and women and imitate the socio-cultural life of their parents, is described below in a play game titled; Đevi-metsitsiwo (Children as adults).

\section{5 Đevi-metsitsiwo}

This type of indigenous game is what I term as 'make-belief', 'role play' or imitation game. In this game, children or the youth, within the age range of 5-14 years, observe, imitate and mimic daily social, political, religious, economic and household activities engaged in by the elderly in the society. It is not surprising, therefore, to see on play grounds, girls imitating their mothers by engaging in household chores such as cooking food in pieces of broken pots, bowls or tins, bathing, feeding and cuddling dolls or pieces of wood assumed to be newly-born babies. The boys act as husbands, elders or chiefs and imitate how the men folk undertake traditional vocations like farming and hunting.

Lancy $(2002 ; 2007)$ similarly comment that "these children engage in pretend activities that imitate and mirrow adult subsistence activities. For example, the boys play with bows and arrows imitating hunting actions and girls grinding flour into tacos and weaving baskets as their mothers do. Furthermore, Mwenda (2014:80) cites the children of Gusii ethnic society in Kenya as they engage in rhythmic and simulation games: 
.....in imitation games, children or the youth play games that are relevant to their future adult-related roles. While the girls play games related to domestic chores, boys participate in more aggressive activities such as parrying and grazing of animals which are all meant to prepare them for their relevant adult roles.

This social behaviour of 'role play' attitude by the youth or children is equally exhibited in their musical activities. During communal Ewe musical performances, children imitate adult ways of music-making. They pretend to be adults by engaging in music and dance performances and accompanying songs with improvised musical instruments such as empty cans, discarded plastic buckets, pans, and pieces of wood or any available object they can lay hands on around them. This observation concurs with what Munyao (2010) similarly observes about children in the Gusii society of Kenya that they readily explore the natural environment and gather available local materials to make their play equipment which they find easy to improvise. Nketia's (1974:60) comment on early childhood exposure to music in Africa explains and gives a deeper understanding of why children's interest in imitation and role play games especially in the typical rural African communities, to date, have not gone extinct:

Informal music training is established when the African mother sings to the child right from cradle and makes him/her aware of rhythm and movement by rocking him and singing to him vocables imitative of drum rhythms. The use of the eyes, ears and memory in addition to participating and imitating the elderly during performance enables the child to acquire musical knowledge through slow absorption which eventually becomes part and parcel of him/her at the stage of adulthood.

\subsubsection{Rules Governing the Performance of the Game}

Though the game of devi-metsitsiwo does not employ strict rules governing its performance, it is however, incumbent on every participant to avoid shyness and timidity in the execution of the adult roles that he/she has been assigned. A child, who feels jittery in the execution of an adult role, is at times laughed at. This form of humiliation urges the culprit on to do the right thing in order to avert further forms of ridicule from his/her fellow colleagues. A high sense of commitment and tolerance is expected of every participant during performance.

\subsubsection{Cultural Essence of the Game of Đevi-metsitsiwo}

Similar to what obtains in Eweland, Manganye (2011:14), highlights the essence of singing games of the Tsonga of South Africa as a means of preserving the musical heritage of the Tsonga culture as well as her indigenous language. With this, the society nurtures children towards adult life and provides through their play-games a platform for acquiring their mother tongue and learning lessons that focus on adult activities in the song texts. The game also offers children values and virtues that are utilitarian to adult life, for, it makes them receptive to many social skills and enables them to shed off anti-social antics; timidity and introvert tendencies which inhibit group cohesion. The game also helps the children to control anger, manage conflicts such as overcoming accusations from play mates, and coping with diverse opinions from fellow colleagues.

One can also observe on the play ground, that the game helps to promote the social development of the children. With their fore knowledge of the game which aims at imitating the socio-cultural life-styles of the elderly in the society, it beholds on every participant to exhibit a high sense of self-control, tolerance, critical thinking and the ability to exhibit good performance skills similar to what their parents do.

Lessons drawn from this indigenous game also enhance the use of different societal skills (both musical and non-musical), that prepare them towards adult life. In other words, the game paves the way for these future leaders to perfect their skills as they grow into adults who would take charge of the responsibility of maintaining and ensuring proper administration and preservation of the indigenous institutions such as the social, political economic, religious systems and musical culture of the society.

\subsection{Gbjtokrolo}

This is an entertaining play and singing game which is exclusively, a preserve of adolescent girls, who after experiencing menstrual flow for the first time; go through a traditional process of gbelelekJnuwJwJ or gbstoksnuwawa (puberty ritual performance). The northern Ewes of Ghana refer to this female game as gbstokrolo. Tracing the origin of the name of this game, gbsto as indicated earlier, means menstrual flow, but krolo is a corrupted Ewe name for akrolo, a recreational game similarly performed by adolescent girls who have experienced their first menstruation among the Akan ethnic group of Ghana. The Ewes might have adopted this game of Akan origin due to a long lasting interaction that existed between these two ethnic groups before the advent of the Europeans in the Gold Coast around the $15^{\text {th }}$ century. 
Symbolically, gbstokrolo is performed to publicly announce the transition of girls from adolescent to adult or marriageable stage. It is also performed to show appreciation to the gods of the land for protecting the initiates and to congratulate the girls for maintaining their chastity and not falling victims of pre-mature pregnancy, an attitude which is culturally considered disgraceful to the girl, her family and the entire society. Though the game is exclusively for adolescent girls, it is never surprising at times to see adult women participating and playing leading roles by teaching the songs and dance-styles and explaining the meaning of some of the songs that centre on their rights and responsibilities. The performance of gbstokrolo is; therefore, open to both adolescent girls ritually initiated and adult women in their prime. Other adult women who are present on the playgrounds are either spectators or act as chaperones.

\subsubsection{Organisation and Performance}

The game takes place in the evenings under moon-lit night in an open arena or any area in the vicinity considered spacious enough. The performance commences when women, who number about fifteen or more, form a circle, hold their hands and while they sing, they swing their arms gently forward and backwards. Since the performance comprises mainly of songs, varied body movements and dance styles, one person is chosen as a cantor and she first tunes up the opening sections of the repertoire of songs before the larger group of the participants join in to sing the remaining portions of each of the songs to the end in a call and response form.

Instruments are not played in the game to accompany singing and dancing; however, clapping of hands is adopted to charge the performance atmosphere. During the music rendition, various body movements and dance steps are executed. At times, the texts of the songs featured during performance demand that the girls take turn to enter the circle and exhibit individual dance prowess to outdo the skills displayed by their fellow participants. While in the circle, a dancer holds a smoldering piece of wood and while dancing, she twirls, wriggles her hips and swings the end of the wood with fire around her head.

As the song approaches its end, she simulates the insertion of the beaming fire between her legs. According to Ewe tradition, the assorted movements and dance styles were considered in the past as ways of projecting the strength, intelligence, agility and dance skills of a performer; a fate which can win her admirers and male suitors. The fire symbolically represents light and employing it in a dance performance does not only depict the girls' duties and responsibilities that illuminate the norms and values of Ewe culture, but also a lady who has a crystal clear mind and conscience that depict female identity and pride in Eweland.

\subsubsection{Rules Governing Gbstokrolo}

As a rule, there is a high expectation of flexibility in body movements in terms of spinning, twirling and wriggling of the hips during the dance performances in order to depict the feminine nature of women. Every form of shyness or timidity during performance is frowned upon. Participation in the above game is closed to children (both boys and girls) as well as girls who have not as yet undergone puberty rites.

\subsubsection{Cultural Relevance of Gbjtokrolo}

The game provides an appropriate platform for girls who have undergone initiation rites to interact amid themselves and share their feelings and pleasures together. The songs are didactic and infused with lessons on marriage and sex issues. Most of the song texts employed in this game centre on sex issues and are, therefore, full of profane words such as outright mentioning of the male and female reproductive organs. The song texts also portray sexual scenes and talk about interactions between the male and female genital organs. These words under normal circumstances, according to Ewe tradition, are not mentioned publicly, however, for the sake of this game, adolescent girls who have undergone puberty rites are deemed to be of age enough to listen to adult talk. For this reason, the profane song texts sung in gbtokrolo are not at all considered inappropriate for these new adults because they are considered to be of age, and for that matter, their activities are permissible and deemed culturally correct.

Gbstokrolo provides a cultural leeway for the budding female adults to openly talk about or discuss issues about male-female relations without the feel of guilt or approbation. In other words, the above issues which were in the past shelved, are now couched in music and dance that accompany this indigenous game. Since the performance is transmitted orally from one generation to the next, the game helps to preserve the musical heritage of the Ewe community. In the light of the above, Muganye (2011) further posits:

Singing games are means of preserving musical heritage and indigenous language. The regular performance of these songs is memorable and, also gives lessons on how females should live good societal life, maintain personal hygiene, care for their babies, treat their husbands and manage their homes. 
The interaction between the young and the elderly women enhances the transfer of knowledge and experiences from the elderly to mould and shape the conduct of the young ladies who are now adults. The song below, talks about the beauty of a girl, whose body contour and flexible dance movements makes her irresistible to every man who sees her for the first time.

\section{O! tughe ka fagnugowoe si?}

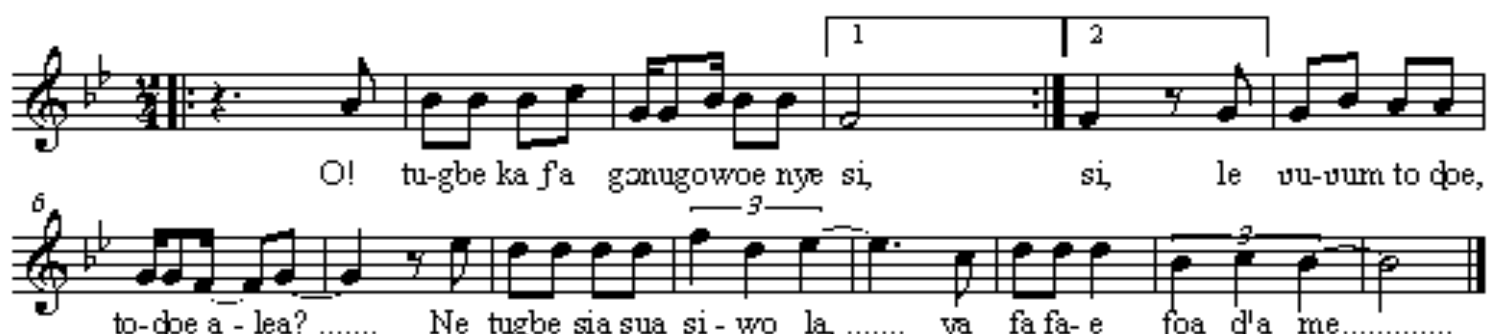

O! tugbe ka f'ag गnugowoe nye sia? Oh! What a pair of buttocks of a beauty?

Le vuvum to dotoqoe alea?

So wriggling and bobing up and down?

Ne tugbe sia su asiwo la

If you possess such a lady for keeps

Ya fafae foa d'a me

Cool air will continuously blow over you.

\subsection{Sibesibe}

Sibesibe, which in Ewe language literally means, run and hide, and similar to the western game of hide and seek, is an indigenous play game performed by children or adolescent boys and girls. The elders found at the periphery of the playground simply act as chaperones or come to watch game for pleasure after a hard day's work on the farm. In this game, one gender, for example, the males take their turn to hide and the females search for them and vice-versa.

The game is usually performed in an open or a spacious area in the community when the moon appears. The boys and girls group themselves into separate groups, and the group that takes the lead in going into hiding is then decided by a toss of a coin. The group that wins the toss first goes into hiding and the other group goes out to search for them in their hideouts. To succeed as victors in this game largely depends on the efficiency of each of the groups and how well their members co-ordinate with each other. For example, members of the group that go into hiding have to be discreet to avoid being caught because if a member is caught, the entire group loses. On the other hand, if a member of the group that goes into hiding succeeds in outwitting those in the search party and reaches the starting point; their group emerges as the winner. It is imperative that those who embark on the search, co-ordinate, and listen to instructions/directions from a team leader, in order to strategise by dispersing and positioning themselves at vantage points on the playground to fish out their opponents from their hideouts.

\subsubsection{The Rules of the Game}

It is required of the members of the group that stays behind to close their eyes while their colleagues go into hiding. This is done to prevent them from watching their colleagues as they move to their hide-out spots. After they close their eyes for some time, they shout out a question; 'evगa?', meaning 'finished?' in order to ascertain whether or not every member of the group has totally gone into hiding. When they hear a response; 'mevo o!', to the question, it means they are still loitering about in search for places to hide. However, when there is no response to the question asked, it means their colleagues have gone into hiding and thus, giving the search party, the license to begin to look for those hiding. There is a clear understanding among the participants that if any member of the group that goes into hiding makes his/her way back to the starting point unnoticed or any member of the search party who is able to catch someone from his/her hideout, in either case, it signifies victory for each of the particular group concerned.

\subsubsection{Socio-cultural Relevance of the Game of Sibesibe}

According to Ewe tradition, the relevance of sibesibe in the first place, helps the participants to take cover; a strategy that was used in the past by their forebears to attack their enemies during inter-ethnic wars that occurred. The game also teaches the youth and children, techniques of hiding personal or family treasures from inquisitive eyes or thieves.

The functions of this play game also can best be described in the words of Clements, Messanga and Millbanks (2008) when they state; "it is a major contributor to enhancing youth or children's physical and mental health because part 
of the game involves running, stooping and jumping and by so doing, improves their imagination and problem-solving skills". As a traditional game, it teaches the need and value of teamwork. Emerging as victors in this game, to a large extent is dependent on the efficiency and co-ordinated efforts of each member of the two participating groups. In other words, the game teaches and develops healthy communal and team spirit instead of relying on individual efforts. These efforts, at the long run help the participants at their adult stages, to build leadership qualities that challenge them to be alert, smart, cooperative and self-committed in their daily activities.

\subsection{Dae qe megbe}

One of the avenues through which boys and girls between the ages of 5-14 years acquire societal values such as vigilance, self-concentration and commitment, smartness as well as building a good team spirit and co-existence, is through partaking in Dae de megbe, a traditional play game that is performed while the participants squat in a circle.

\subsubsection{Organisation and Performance}

The participants, both boys and girls, squat in a circle and while they sing in a call and response pattern, one member, usually a cantor, runs round the human circle and deposits either a piece of cloth, handkerchief or an object behind an unsuspecting member. By the rules of the game, every participant is required to be alert and intermittently cross-check if something has been deposited behind him/her. If the cantor goes round the circle and returns to find the object still at where he deposited it, he/she hits the culprit mildly at the back to draw his/her attention to what is behind him/her. However, if the person behind whom the object is deposited suspects this earlier, he/she quickly picks the object and runs fast to catch up with the cantor in order to hit him/her. If the cantor is hit, he/she still continues the game by going round the circle. On the other hand, if the cantor is fast enough to run and occupy the place of the one chasing him, the cantor's role and conduct of the game now shifts to the new person. This format is followed until the participants become tired and retire.

\subsubsection{Rules Governing dae de megbe}

As the name of the game implies, dae de megbe (deposit it behind), is the paramount rule that specifically locates where the piece of cloth or object handled by the cantor during the game should be deposited. No participant is allowed to turn back to look at the cantor while he/she runs round the human circle. The rule also bars participants from alerting a member who has not noticed that an object has been placed behind him/her. The rule of the game also stresses the fact, that in the context of play, hitting a member on the back for non-detection of the object behind $\mathrm{him} /$ her does not generate loathing or fight.

\subsubsection{Relevance of the Game}

The game helps children to acquire virtues of alertness, vigilance, self-consciousness, discipline and tolerance in the participants, and as they grow into maturity, these internalised societal values serve as a foundation for managing and controlling their adult life styles with a sense of purpose and dignity. That is why participants, who lack such qualities, mentioned above, are lost in the fun of the game and fail to realise what has been placed behind them. To avert this situation, they are immediately alerted through the gentle strike they receive at their backs in order to be self-conscious or vigilant. The Ewe society, therefore, places premium on why it is vital for young citizens to quickly discern happenings or challenges around their homes, surroundings, and the community, for, it helps them to take appropriate steps to solving such challenges in order to build a strong, healthy and united society in future. One can, therefore, not dispute the fact that the game helps to strengthen the agility and smartness in the young, and shapes them to be fast and critical thinkers. Amlor and Alidza (2009) sum up the relevance of this indigenous game by stating that "engagement in the activities of this game enables children to acquire norms, values and societal skills that foster self-usefulness and help them to be able to perform expected future roles as adults".

\section{The Way Forward}

Though western cultural pressure in terms of what Goslin \& Goslin (2009) describe as combined effects of economic, social and environmental changes that are encroaching upon various indigenous games and creating a high risk of losing these games to western influenced modern games" is plausible, this paper does not aim at outrightly condemning foreign cultural influences, but instead, suggests the adoption of only aspects that can enhance Ghanaian indigenous knowledge and project the people's cultural identity. In this direction, the media, composers/arrangers, researchers and performers should be aware of the essence of the country's folklores which include play and singing games and consequently protect and re-tool them to educate especially, the youth. If the aim of the mass media (both print and electronic) is to inform, educate and entertain the public, the bulk of items that constitute its programmes 
should reflect the indigenous education of listeners/viewers in the society they are located. This would enable the people to understand and take pride in their cultural heritage.

The government of Ghana through its agencies like the Ministry of Education, the universities and other stakeholders in the educational sector should be conscious of the fact that the majority of the products from the basic schools, colleges/universities would serve as future professionals in African societies. The need for collaborative efforts of the above named agencies to conduct research that can lead to producing African-centred school curricula which can incorporate the teaching of folklores, play and singing games, music, dance, alongside other cultural values to constitute part and parcel of formal education, to ensure indigenous knowledge acquisition in a fast and playful manner, is very crucial. Frost (1992) also recommends that "teachers must regularly observe children at play so as to obtain information that identifies those with special needs, planning future play experiences, evaluating play materials, determining their strengths and weaknesses and planning suitable curriculum for early childhood education. Through such observations, teachers can learn about children's social interactions, cognitive and language abilities, motor skills and emotional development". This move has been successful in African countries such as South Africa and Nigeria and the possibility of replicating it in Ghana can equally yield positive results.

Nketia (1970) corroborates the above point when he opines:

Singing and studying folk songs should be the cornerstone, especially at the first stages of musical education. The folk song in its pure form and beauty should be more widely represented in the school curricula than it has been so far. Obviously, it is not necessary, and hardly possible, to try to fence our young people off from the light and popular music that they like to hear in their leisure time. But it is necessary to teach them to distinguish between the good and bad, trite and tasteless. Knowledge of the best examples of folk music......will help the youth to assess musical information and set up immunity to the corrupting influence of its worst manifestations.

Nurturing children through African-centered education is what Amlor (2011:28) stresses as: "that which will in future, make them champions of their professions, culture and reservoirs of indigenous education that would not only benefit the youth of today, but also help them to preserve and transfer the acquired knowledge to the generation yet to succeed them".

\section{Conclusion}

The extent to which foreign culture is stifling native Ghanaian values has led to a re-awakening among Ghanaian Ewes to go back to their roots and revive youth or children's indigenous entertainment forms such as play games to promote the teaching, learning and acquisition of indigenous education that can nurture them to maturity, and empower them to assume responsible future adult roles in the society.

Six indigenous games/entertainment forms which constituted the focus of this study included: Ka asi atiasimake (Touch the untouchable tree), Amesi wodzi Dzoda (Whoever is born on Monday), Đevi-metsitsiwo (Children as adults), Gbstokrolo (Puberty initiates' singing game), Sibesibe (Run and hide) and Dae de megbe (Deposit it from behind). The performance of each game is governed by a set of rules. The rules, though simple, help in developing the cognitive and effective domains of the participants. The games which often incorporates music and dance performances, offer the youth or children the opportunity to unconsciously learn lessons and societal ethics very quickly in a playful manner. Other values acquired from participating in these play games include: the ability of the young to cultivate good behaviour, tolerance, discipline, healthy spirit of co-existence, leadership qualities, hard work, and competitive spirit. In other words, the relevance of indigenous Ewe play games give children cultural identity that enables them to acquire norms, values and societal skills that foster self-usefulness and help them to perform expected future roles as adults. The games that involve running, jumping, squatting and other body movements are indirect forms of physical and mental exercises that keep the bodies and minds of the children healthy. These varied forms of activities underpin the old adage that states: "a sound mind in a healthy body". All these go in line with the Vygostskian theory of early childhood development which states that "children do not only practise what they already know but also learn new things" (Vygotsky, 1978).

Since Ewe, constitutes the core language of communication in the games, Amlor and Alidza (2009:120) point out an important value that children derive from the use of their mother-tongue as they participate in these play games:

"language comprises difficult words including tongue-twisters. Tongue-twisters as important cultural elements employed in recitative or declamatory style of singing during children's play games, enhance their 
diction and eloquence and, as well, provide them the opportunity to gain easy and quick mastery of difficult words and phrases that occur in songs or in ordinary speech".

The paper finally draws attention to the need for nurturing children through an African-centered education. To achieve this goal, there is the need for the government of Ghana through its agencies such as the Ministry of Education, the universities and other stakeholders to collaborate and conduct research that can come out with African-centred school curricula for use in the schools. A move towards incorporating topics on folklores; play and singing games, music and dance, alongside other cultural values to constitute part and parcel of formal education and taught right from pre-school to higher institutions of learning in contemporary Ghana, is, therefore, crucial.

\section{References}

Amlor, M.Q. (2011). Oguaa Fetu Afahye: A music and ritual of the people of Cape Coast in Ghana. In Music and ritual; Musika Jornal, University of the Philippines, 7, 6-32.

Amlor, M.Q., \& Alidza, M.Q. (2009). Language, music and identity: A socio-cultural insight into the Ewes of Ghana. Gumaga: International Journal of Language and Literature, 2, 107-130.

Cheska, A.T. (1987). Tradtional games and dances in West African nations. Schorndorf: Verlag Karl Hofmann.

Clements, R., Messanga, M., \& Millbank, A.N. (2008). Traditional children's games in Tanzania. Children, youth and environments, 18(2), 206-218.

Creswell J.W. (2005). Educational research: Planning, conducting and evaluating quantitative and qualitative research. Upper Saddle River: NJ: Merrill Prentice Hall, 8.

Fontana, A., \& Frey J.H. (1994). Interviewing: The art of science. In N.K. Denzin \& Y.S. Lincoln (Eds.), Handbook of qualitative research, Thousand Oaks, CA: Sage Publications.

Frimpong-Nnuroh, D. (2010). The scientific basis of some Ellembelle Nzema indigenous knowledge forms. In D.D. Kupole \& Botchway, D.N.Y. (Eds.), Polishing the pearls of ancient wisdom: Exploring the relevance of endogenous African knowledge systems for sustainable development in post-colonial Africa. University of Cape Coast Printing Press.(pp. 99-118).

Frost, J.L. (1992). Play and playscapes. Albany, New York: Delmar, G.

Garvey, C. (1990). Play. Cambridge, MA; Harvard University Press.

Goslin, A., \& Goslin, B. (2009). Traditional games in the Tswane area of South Africa: A comparative study. In L.O Amusa \& A.L. Toriola (Eds.), Tradtional games in Africa. South Africa (pp.94-104). WWW publishing (pty) Ltd.

Holmes, R. (2011). Adult caregiver attitudes and beliefs regarding play in Lana'i. American Journal of Play, 3, 424-452.

Huizinga, J. (1950). Homo ludens: A study of the play element in culture. New York: Roy.

Kenyatta, J. (2004). Facing Mount Kenya: The traditional life of the Gikuyu $\left(14^{\text {th }}\right.$ Ed.). Nairobi: Kenway Publication.

Lancy, D. (2002). Cultural constraints on children's play. In Roopnarine, J. (Ed.), Conceptual, social-cognitive and contextual issues in the fields of play. Play and Culture Studies, 4, 53-62.

Lancy, D. (2007). Accounting for variability in mother-child play. American Anthropologist, 109(2), 273-284. http://dx.doi.org/10.1525/aa.2007.109.2.273

Manganye, N.N. (2011). Indigenous children's game songs. Unpublished dissertation. University of Pretoria, South Africa Merriam-Webster Dictionary, Retrieved from http://www.merriam-webster.com/dictionary/singing\%20game

Munyao, R.K. (2010). The traditional games of the Akamba of Kenya. Unpublished M. Phil. Thesis, Kenyatta University, Kenya.

Mwenda, P.W. (2014). Elements of traditional games of the Gush Community of Kenya. Unpublished M. Phil. Thesis. Kenyatta University, Kenya.

Ndee, H.S. (2010). Prologue: Sport, culture and society in Tanzania from and African erspective. The International Journal of History of Sport, 27(5), 733-758. http://dx.doi.org/10.1080/09523361003625808 
Nketia, J.H. (1974). Music of Africa. London: Victor Gollancz Ltd.

. (1970). Music Education in Africa and the West: We can learn from each other. Music Educators Journal, 3(3), 48-55. http://dx.doi.org/10.1177/002743217005700313

Nyato, S., \& Mpara, J. (2008). Shona traditional children's games and play: Songs as indigenous ways of knowing. The Journal of Pan African Studies, 2(4), 189-202.

Sutton-Smith, B., Mechling J., \& T. W. Johnson. (1995). Children's Folklore: A Source Book. London: Taylor \& Francis, pp. 11-16.

Vygotsky, L. (1978). Mind in society: The development of higher psychological processes. Cambridge, MA: Harvard University Press.

Wanderi, P.M. (2009). Traditional games in Africa: East and Central Africa. In L.O. Amusa \& Toriola, A.L. (Eds.), Traditional and indigenous games and sports in Africa (pp.1-7). South Africa: WWW Publishing (pty) Ltd.

. (2011) The Indigenous games of the people of coastal region of Kenya: A cultural-educational appraisal. Ethiopia, Addis Ababa: Organisation for Social Science research in Eastern and Southern Africa (OSSREA). 